\title{
REVIEW
}

\section{Gut microbiome-host interactions in health and disease}

\author{
James M Kinross', Ara W Darzi' and Jeremy K Nicholson*2
}

\begin{abstract}
The gut microbiome is the term given to describe the vast collection of symbiotic microorganisms in the human gastrointestinal system and their collective interacting genomes. Recent studies have suggested that the gut microbiome performs numerous important biochemical functions for the host, and disorders of the microbiome are associated with many and diverse human disease processes. Systems biology approaches based on next generation 'omics' technologies are now able to describe the gut microbiome at a detailed genetic and functional (transcriptomic, proteomic and metabolic) level, providing new insights into the importance of the gut microbiome in human health, and they are able to map microbiome variability between species, individuals and populations. This has established the importance of the gut microbiome in the disease pathogenesis for numerous systemic disease states, such as obesity and cardiovascular disease, and in intestinal conditions, such as inflammatory bowel disease. Thus, understanding microbiome activity is essential to the development of future personalized strategies of healthcare, as well as potentially providing new targets for drug development. Here, we review recent metagenomic and metabonomic approaches that have enabled advances in understanding gut microbiome activity in relation to human health, and gut microbial modulation for the treatment of disease. We also describe possible avenues of research in this rapidly growing field with respect to future personalized healthcare strategies.
\end{abstract}

*Correspondence: j.nicholson@imperial.ac.uk

${ }^{2}$ Section of Bimolecular Medicine, Department of Surgery and Cancer, Faculty of Medicine, Imperial College London, The Sir Alexander Fleming Building, South Kensington, London SW7 2AZ, UK

Full list of author information is available at the end of the article

\section{The medical importance of the human microbiome}

The human intestine carries a vast and diverse microbial ecosystem that has co-evolved with our species and is essential for human health [1,2]. Mammals possess an 'extended genome' of millions of microbial genes located in the intestine: the microbiome [3]. This multigenomic symbiosis is expressed at the proteomic and metabolic levels in the host and it has therefore been proposed that humans represent a vastly complex biological 'superorganism' in which part of the responsibility for host metabolic regulation is devolved to the microbial symbionts [4]. Modern interpretation of the gut microbiome is based on a culture-independent, molecular view of the intestine provided by high-throughput genomic screening technologies [5,6]. Also, the gut microbiome has been directly implicated in the etiopathogenesis of a number of pathological states as diverse as obesity [7], circulatory disease [8], inflammatory bowel diseases (IBDs) [9] and autism [10] (Figure 1). The gut microbiota also influence drug metabolism and toxicity [11], dietary calorific bioavailability [12], immune system conditioning and response [13], and post-surgical recovery [14]. The implication is that quantitative analysis of the gut microbiome and its activities is essential for the generation of future personalized healthcare strategies [15] and that the gut microbiome represents a fertile ground for the development of the next generation of therapeutic drug targets. It also implies that the gut microbiome may be directly modulated for the benefit of the host organism.

The gut microbiota therefore perform a large number of important roles that define the physiology of the host, such as immune system maturation [16], the intestinal response to epithelial cell injury [17], and xenobiotic [18] and energy metabolism [7]. In most mammals, the gut microbiome is dominated by four bacterial phyla that perform these tasks: Firmicutes, Bacteroidetes, Actinobacteria and Proteobacteria [19]. The phylotype composition can be specific and stable in an individual [20], and in a 2-year interval an individual conserves over $60 \%$ of phylotypes of the gut microbiome [21]. This implies that each host has a unique biological relationship with its gut microbiota [22,23], and by definition that this influences an individual's risk of disease. The gut microbiome varies 


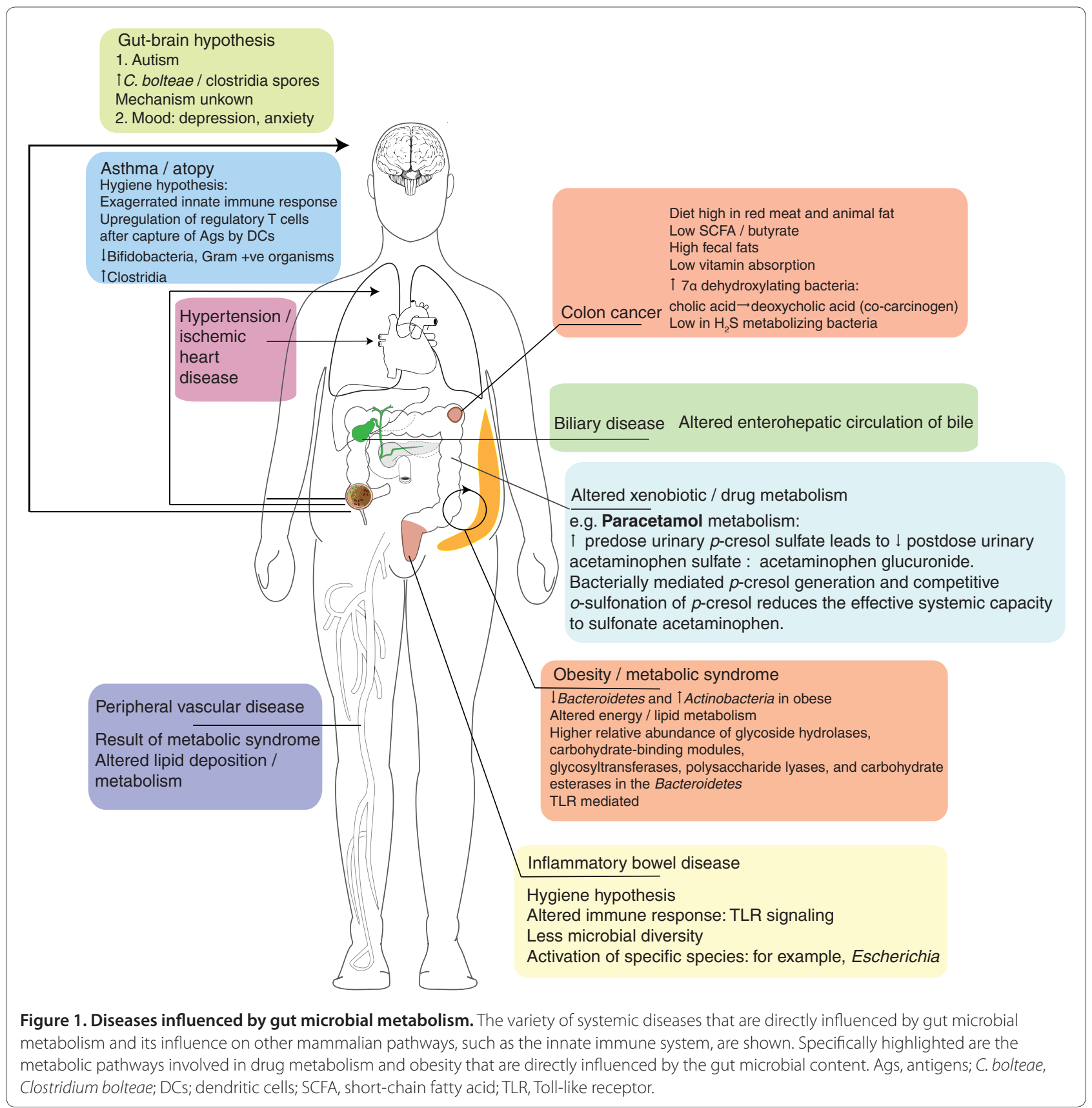

between species and, as a result, in vivo models utilizing gnotobiotic rodents or pigs conventionalized with human baby flora (HBF) have been adopted to permit more accurate modeling of the human gut [24]. Future experimental models must also accurately replicate the metabolic function of the gut microbiome [25]. For this to occur, the 'healthy' intestinal microbiome must first be understood; for example, differences between individuals are known to be more marked among infants than in adults [26], but later in life the gut microbiome converges to more similar phyla. It is not yet known how such an important symbiotic relationship, even in apparently well neonates, influences long-term health outcome. Therefore, there is now a significant effort to define a 'core' microbiome to determine the role played by the gut microbiome in diseases across geographically diverse populations [6]. Here, we review recent studies that have provided important insights into the human gut microbiome, and the functional role of the gut microbiome in health, disease and in drug efficacy. We review current methods for the modulation of the gut microbiome for the improvement of human health and disease, and 
assess the translational and therapeutic implications of this rapidly evolving area of research.

\section{Recent insights into gut microbiome variation and activity}

The advent of 16S rRNA gene-sequence-based methods [27] has led to the description of the substantial diversity of the gut microbiome between healthy individuals [28-30]. It has also led to new insights into the presence of particular species and strains in the human gut and their variance between intestinal locations and species of mammal. For example, 16S RNA approaches have been used to study the maturation of murine cecal microbiota, and they have demonstrated the existence of a large number of yet unidentified bacteria that inhabit it [31]. Such 'culture-independent' techniques are used to measure the stability of the microbiome over time and its stability when transferred between species. This is essential for building robust experimental models for the human microbiome and for delineating important mechanistic processes in the development of human disease states. Genomic strategies, such as denaturing gradient gel electrophoresis (DGGE) of 16S rRNA sequences, have commonly been employed for this purpose. Analysis of human microbiota-associated (HMA) rat feces using this approach has revealed that the Bacteroides/Prevotella and Faecalibacterium species are dominant in both humans and HMA rats post-transfection [32]. However, HMA rats also possessed Ruminococcus, which was not present in the human DGGE profile. With this exception, the sequences originating from both rats and human samples were represented in all major branches of a nonparametric statistical method for computational phylogenetics known as a maximum parsimony tree. Analysis of 16S rRNA analysis has also provided new insights into the Cytophaga-Flavobacterium-Bacteroides phylum, which has recently been found to be common to the intestines of mice, rats and humans [33].

Recent advances in sequencing technologies have led to the wider use of metagenomic analysis for studying complex ecosystems such as the human gut [34-36], and some key findings from human studies are outlined in Table 1. This approach functions on the principle that the genome sequences of abundant species will be well represented in a set of random shotgun reads, whereas species with lower abundance may be represented by a small number of sequences, thus permitting the comprehensive measurement of the response of an ecosystem to an environmental perturbation or therapeutic intervention. This technology brings with it the significant challenge of managing vast data sets. For example, in three separate studies $3 \mathrm{~Gb}$ of microbial sequences were generated from fecal samples of only 33 individuals from the USA or Japan [2,29,37]. Advances in analytical approaches are only exacerbating this problem and in a separate analysis $576.7 \mathrm{~Gb}$ of sequence, almost 200 times more than in all previous studies, was generated using an Illumina ${ }^{\mathrm{TM}}$ Genome Analyzer (Illumina, San Diego, CA, USA) for deep sequencing of total DNA from fecal samples of 124 European adults (Table 1).

However, metagenomic sequencing of the gut microbiome has some limitations. The intestinal epithelium is composed of three functional barriers: a physical barrier, an innate immune barrier and an adaptive immune barrier [38]. The relationship between commensal gut flora and the intestinal barrier is complex, and occurs at each of these interfaces, and fecal metagenomics does not therefore measure ecosystem changes at all levels. Also, metagenomic analysis of fecal samples does not provide a comprehensive picture of important molecular interactions within the complex topography and niches in the gut. Nonetheless, metagenomic analysis does permit some inference of functional information. Gill et al. [2] reported the variation between two individuals in the distal gut metagenome. The authors described statistically significant variability in the enrichment of several classes of genes involved in energy metabolism, carbohydrate, amino acid and nucleotide transport and co-enzyme transport. Clusters of orthologous groups analysis also revealed the under-representation of genes involved in secondary metabolite biosynthesis, and inorganic ion transport and metabolism in the human distal gut microbiome (Table 1). This suggested that there is significant interindividual and interspecies variability.

The key aim of the majority of this work has therefore been to try and define a 'core microbiome'. This is an important aim, as it implies that we all share a key number of essential species or strains that help to define human health and, more importantly, that can then be mined for drug targets. Data from these studies have been conflicting on this point. Turnbaugh et al. [39] recently concluded that a core microbiome based on species or strain data may not be present, because their data demonstrated that by adulthood no single bacterial phylotype was detectable at an abundant frequency in the guts of all 154 humans sampled in their metagenome wide study. Qin et al. [6] reported the definition of the minimal core microbiome: $576.7 \mathrm{~Gb}$ were sequenced from 124 individuals, and this demonstrated that 18 species were found in all individuals; 57 species were demonstrated in $\geq 90 \%$ of the study cohort, and 75 species were found in $\geq 50 \%$ of the study cohort. However, this may reflect a different analytical approach, and this study also employed a cohort of patients with IBD. Therefore, it may be that the gut pathology aligns the gut microbiota, and reduces the variability found in a healthier populace. Turnbaugh et al. have argued that a core microbiome may exist at a functional level (for example at a genomic, 
Table 1. Human metagenomic studies that have studied the distal gut microbiome

\begin{tabular}{|c|c|c|c|c|c|}
\hline Study & $\begin{array}{l}\text { Number of } \\
\text { humans }\end{array}$ & $\begin{array}{l}\text { Sequencing } \\
\text { technology }\end{array}$ & Sequence length & Phylogenetic data and key findings & $\begin{array}{l}\text { Gene function (for example, KEGG/COG- } \\
\text { enriched processes) }\end{array}$ \\
\hline $\begin{array}{l}\text { Gill et al. } \\
(2006)[2]\end{array}$ & $\begin{array}{l}2 \text { (1 male, } \\
1 \text { female, } \\
\text { healthy) }\end{array}$ & $\begin{array}{l}\text { ABI } 3730 x \mid \\
\text { sequencer } \\
\text { (Applied } \\
\text { Biosystems) }\end{array}$ & $\begin{array}{l}\text { 17,668 contigs; } \\
\text { 14,572 scaffolds; } \\
\text { 33,753,108 bp; } \\
\text { 50,164 ORFs; } \\
\text { 19,866 unique } \\
\text { database matches } \\
\text { predicted }\end{array}$ & $\begin{array}{l}72 \text { bacterial phylotypes identified; } 1 \\
\text { archaeal phylotype (Methanobrevibacter } \\
\text { smithii); } 16 \text { novel bacterial phylotypes. } \\
\text { Phylotypes assigned: Firmicutes ( } 62 \\
\text { phylotypes, } 105 \text { sequences) and the } \\
\text { Actinobacteria (10 phylotypes, } 27 \\
\text { sequences) }\end{array}$ & $\begin{array}{l}\text { Energy production and conversion; carbohydrate } \\
\text { transport and metabolism; amino acid transport } \\
\text { and metabolism; coenzyme transport and } \\
\text { metabolism; secondary metabolites biosynthesis, } \\
\text { and transport and catabolism; MEP pathway for } \\
\text { biosynthesis of DXP and IPP; } \beta \text {-glucuronidase } \\
\text { activity induced }\end{array}$ \\
\hline $\begin{array}{l}\text { Kurokawa } \\
\text { et al. (2007) } \\
\text { [37] }\end{array}$ & $\begin{array}{l}7 \text { adults, } \\
2 \text { children } \\
\text { and } 4 \\
\text { unweaned } \\
\text { infants } \\
\text { (Japanese } \\
\text { and } \\
\text { Japanese } \\
\text { American) }\end{array}$ & $\begin{array}{l}\text { ABI } 3730 \\
\text { sequencers } \\
\text { (Applied } \\
\text { Biosystems) } \\
\text { or the ET } \\
\text { chemistry on } \\
\text { MegaBACE4500 } \\
\text { sequencers (GE } \\
\text { Healthcare) }\end{array}$ & $\begin{array}{l}1,057,481 \text { shotgun } \\
\text { reads representing } \\
\text { sequences of } 727 \\
\text { Mb; total length } \\
\text { of the contigs } \\
\text { and singletons } \\
\text { from } 13 \text { samples } \\
\text { was } 478.8 \mathrm{Mb} \text {; } \\
\text { identified } 20,063 \\
\text { to } 67,740 \text { potential } \\
\text { protein-encoding } \\
\text { genes }\end{array}$ & $\begin{array}{l}\text { 17\% to } 43 \% \text { of predicted genes } \\
\text { assigned to particular genera ( } 35 \text { to } 65 \\
\text { genera, } 121 \text { in total). } \\
\text { Adults and weaned children: } \\
\text { Bacteroides and genera belonging } \\
\text { to division Firmicutes (for example, } \\
\text { Eubacterium, Ruminococcus } \\
\text { and Clostridium, and the genus } \\
\text { Bifidobacterium. Infants: Bifidobacterium } \\
\text { and/or a few genera from the family } \\
\text { Enterobacteriaceae, such as Escherichia, } \\
\text { Raoultella and Klebsiella }\end{array}$ & $\begin{array}{l}\text { Carbohydrate transport and metabolism; } \\
\text { under-representation of those for 'lipid transport } \\
\text { and metabolism'; defense mechanisms; cell } \\
\text { motility, secondary metabolites biosynthesis, } \\
\text { transport and catabolism and post-translational } \\
\text { modification and protein turnover; pyruvate- } \\
\text { formate lyase enriched; formate hydrogenlyase } \\
\text { system under-represented }\end{array}$ \\
\hline $\begin{array}{l}\text { Turnbaugh } \\
\text { et al. } 2009 \\
{[39,100]}\end{array}$ & $\begin{array}{l}154 \text { (31 } \\
\text { MZ and } 23 \\
\text { DZ female } \\
\text { twin pairs } \\
\text { and their } \\
\text { mothers } \\
n=46, \\
\text { twins } \\
\text { concordant } \\
\text { for obesity } \\
\text { or leanness) }\end{array}$ & $\begin{array}{l}454 \\
\text { Pyrosequencing }\end{array}$ & $\begin{array}{l}9,920 \text { near } \\
\text { full-length and } \\
1,937,461 \text { partial } \\
\text { bacterial } 165 \text { rRNA } \\
\text { sequences }\end{array}$ & $\begin{array}{l}\text { Gut microbiome shared among family } \\
\text { members; degree of co-variation } \\
\text { between adult MZ and DZ twin pairs; } \\
\text { no single abundant bacterial species } \\
\text { shared by all } 154 \text { individuals; wide array } \\
\text { of shared microbial genes in sampled } \\
\text { general population: 'core microbiome' } \\
\text { at the gene level. } \\
\text { Lower proportion of Bacteroidetes and } \\
\text { a higher proportion of Actinobacteria } \\
\text { in obese subjects and reduced bacterial } \\
\text { diversity. Altered representation } \\
\text { of bacterial genes and metabolic } \\
\text { pathways, including those involved in } \\
\text { nutrient harvest }\end{array}$ & $\begin{array}{l}\text { Total of } 156 \text { total CAZy families found within at } \\
\text { least one human gut microbiome: } 77 \text { glycoside } \\
\text { hydrolase, } 21 \text { carbohydrate-binding module, } 35 \\
\text { glycosyltransferase, } 12 \text { polysaccharide lyase, } 11 \\
\text { carbohydrate-esterase families. Carbohydrate } \\
\text { metabolism pathways enriched in Bacteroidetes } \\
\text { bins; transport systems in Firmicutes bins; } \\
\text { transcription and translation pathways enriched; } \\
\text { carbohydrate and amino acid metabolism; } \\
\text { secretion systems, and membrane transport for } \\
\text { import of nutrients, including sugars varied in } \\
\text { their enrichment }\end{array}$ \\
\hline $\begin{array}{l}\text { Qin et al. } \\
(2010)[6]\end{array}$ & $\begin{array}{l}124 \text { healthy, } \\
\text { overweight } \\
\text { and obese } \\
\text { individual } \\
\text { human } \\
\text { adults; } 21 \\
\text { ulcerative } \\
\text { colitis, } 4 \\
\text { Crohn's } \\
\text { disease }\end{array}$ & Illumina GA & $\begin{array}{l}6.58 \text { million } \\
\text { contigs ( }>500 \\
\text { bp giving a total } \\
\text { contig length of } \\
10.3 \mathrm{~Gb}) ; 576.7 \mathrm{~Gb}\end{array}$ & $\begin{array}{l}\text { Definition of minimal core microbiome: } \\
\text { at } 1 \% \text { ( } 40 \text { kb) coverage, } 18 \text { species } \\
\text { in all individuals, } 57 \text { in } \geq 90 \% \text { and } 75 \\
\text { in } \geq 50 \% \text { of individuals; } 99.96 \% \text { of } \\
\text { the phylogenetically assigned genes } \\
\text { belonged to the bacteria and archaea. } \\
\text { Bacteroidetes and Firmicutes had the } \\
\text { highest abundance. } \\
\text { Network analysis of } 155 \text { species } \\
\text { in at least one individual at } \geq 1 \% \\
\text { coverage had prominent clusters for } \\
\text { Bacteroidetes, Dorea/Eubacterium/ } \\
\text { Ruminococcus, Bifidobacteria, } \\
\text { Proteobacteria and streptococci/ } \\
\text { lactobacilli groups }\end{array}$ & $\begin{array}{l}\text { Genes related to adhesion and harvesting sugars } \\
\text { of the globoseries glycolipids; phage-related } \\
\text { proteins; biodegradation of complex sugars and } \\
\text { glycans, for example, pectin (and its monomer, } \\
\text { rhamnose) and sorbitol; three-quarters of } \\
\text { prevalent gut functionalities from novel gene } \\
\text { families; approximately } 45 \% \text { of functions present } \\
\text { in }<10 \% \text { of the sequenced bacterial genomes }\end{array}$ \\
\hline $\begin{array}{l}\text { Koenig et al. } \\
{[101]}\end{array}$ & $\begin{array}{l}1 \text { infant } \\
\text { over } \\
2.5 \text { years }\end{array}$ & $\begin{array}{l}454 \\
\text { pyrosequencing }\end{array}$ & $\begin{array}{l}318,62016 \mathrm{~S} \text { rRNA } \\
\text { gene sequences }\end{array}$ & $\begin{array}{l}\text { Phylogenetic diversity correlates with } \\
\text { age. Diversity changed gradually in } \\
\text { four discrete phases: (1) days } 1 \text { to 92: } \\
\text { Firmicute OTUs; (2) fever at day 92: } \\
\text { proteobacterial and actinobacterial } \\
\text { OTU abundances, suite of Firmicute } \\
\text { OTUs differed; (3) exclusion of breast } \\
\text { milk; and (4) introduction of peas and } \\
\text { cefdinir use: increase in Bacteroidetes }\end{array}$ & $\begin{array}{l}\text { Carbohydrate metabolism; amylose, arabinose } \\
\text { and maltose degradation; virulence genes } \\
\text { enriched; rhamnose, fructo-oligosaccahride } \\
\text { and raffinose-utilization pathways, and xylose- } \\
\text { degradation genes expressed; lactose/galactose } \\
\text { and sucrose utilization; antibiotic resistance; } \\
\text { vitamin biosynthesis; sialic acid metabolism, } \\
\text { ß-glucoronide utilization; polysaccharide } \\
\text { metabolism (day 371: maltose, maltodextrin, } \\
\text { xylose); xenobiotic degradation; benzoate } \\
\text { catabolism and aromatic metabolism }\end{array}$ \\
\hline
\end{tabular}

Summary of the key experimental findings and the predominant phylogenetic data, and specific pathways and functional pathways highlighted by analysis from the Kyoto Encyclopedia of Genes and Genomes (KEGG) pathways and clusters of orthologous groups (COG) analysis. CAZy, carbohydrate-active enzyme; DZ, dizygotic; DXP, deoxyxylulose 5-phosphate; IPP, isopenteryl pyrophosphate; MEP, 2-methyl-D-erythritol 4-phosphate; MZ, monozygotic; OUT, operational taxonomic unit. Applied Biosystems, Carlsbad, CA, USA; GE Healthcare, Piscataway, NJ, USA; Illumina, San Diego, CA, USA. 
proteomic or metabolic level), meaning that other tools may be required for its further analysis. It also suggests that from a systems perspective we are highly variable with tremendous implications for personalized healthcare strategies. A key question now is: how is this unique ecosystem assembled and maintained within individuals or across species?

Initial metagenomic analysis seems to confirm the stability of some microbial species between animal species. Fecal DNA samples from dogs were analyzed using 454 pyrosequencing [40]. Sequenced data were interpreted by the Meta Genome Rapid Annotation using Subsystem Technology (MG-RAST [41]) and this was compared with paired data from lean and obese mouse cecal metagenomes [7] and two human fecal metagenomes (F1S; HSM) [37]. The Bacteroidetes/Chlorobi and Firmicutes phyla comprised $35 \%$ of all sequences, followed by Proteobacteria (13\% to 15\%) and Fusobacterium (7\% to $8 \%)$. Hierarchical clustering of several gastrointestinal metagenomes demonstrated phylogenetic and metabolic similarity between dogs, humans and mice.

Metagenomic approaches are not just restricted to the analysis of microbial genomes. A more novel area of work relates to the analysis of the interaction of the gut microbiome with gut parasites, viruses, yeasts and fungi, and its importance for human health [42]. Fungal interactions with the distal gut microbiome have yet to be characterized using a metagenomic analysis, although this has been attempted within the oral microbiome using a multitag pyrosequencing approach in 20 healthy individuals [43]. However, the gut virome has recently been investigated. Fecal samples were collected from healthy adult female monozygotic twins and their mothers at three time points over a 1-year period [44]. These datasets were compared with datasets of sequenced bacterial 16S rRNA genes and total-fecal-community DNA. In keeping with other studies reported in the literature, twins and their mothers share a significantly greater degree of similarity in their fecal bacterial communities when compared with unrelated individuals. However, viromes were found to be unique to individuals regardless of their degree of genetic relatedness. Furthermore, intrapersonal diversity was very low, with $95 \%$ of virotypes retained over the period surveyed. These results suggested that the viral-microbial dynamic found in other environmental ecosystems was not present in the very distal intestine. This area of research is likely to become increasingly important as more of the interkingdom signaling pathways are elucidated, and the importance of viral, parasite and fungal mutualism is recognized. Metagenomics therefore represents a growing and important area of research into the gut microbiome, and work in this area continues to generate new, potentially important taxa that are being described [45].

\section{The functional role of the gut microbiome in health, disease and drug efficacy}

Culture-independent genomic strategies are not without limitations because of their inability to infer organismal function from these gene sequences. A genomic strategy will therefore largely only describe the potential for a disease state. Hybrid approaches are thus required to provide temporal information about the actual biological activity of the microbiome. Approaches such as proteomics and metabonomics can thus be used to study the functional capacity of the gut microbiome from the top down $[46,47]$. Real time analysis of the intestinal microbiome is essential for both the development and the monitoring of interventional personalized therapeutic strategies. Metabonomics describes the computational analysis of spectral metabolic data to provide information on time-specific metabolic changes across a complex system [48]. In turn, this has led to the concept of 'global metabolic profiling, which provides a unique overview of the metabolic state of an individual. This is because it is able to indirectly measure complex transgenomic cometabolic interactions that are vital for human health, and which are often modulated by disease [49,50]. The notion of microbial-mammalian metabolic cooperation is defined through the concept of the human metabonome (the sums and interactions of all the cellular metabolomes) [51]. Metabolic profiling coupled with the metagenomic study of the gut microbiota permits the close inter-relationship between the host and microbial 'metabotypes' to be studied in great detail, and provides the basis for further understanding the microbial-mammalian metabolic axis. Ultimately, this has led to the idea of 'functional metagenomics', defined as 'the characterization of key functional members of the microbiome that most influence host metabolism and hence health' [52].

Metabolic profiling strategies, such as high-throughput analysis by NMR spectroscopy or mass spectrometry, are widely used to provide global metabolic overviews of human metabolism $[8,47,48,53-55]$. These methods are used in conjunction with computational multivariate analysis to provide a deeper understanding of disease states and biomarker discovery. This approach allows the quantification of environmental influences on the host genome and human health $[48,55]$. This analytical strategy has now been successfully applied to disease states such as hypertension [8], ischemic heart disease [56], diabetes [57] and obesity [58] as part of large-scale clinical studies. These studies suggest that the intestinal microbiome is essential in determining the metabolic response of the host to environmental stimuli and thus disease. Moreover, the intestinal microbiome is essential for determining the toxic response to pharmacological therapies, and the case of paracetamol permits pre-dose predictions of toxicity to be made $[18,59]$. 
The systematic characterization of the metabolic content of aqueous fecal extracts across humans, mice and rats has been performed using high-resolution NMR spectroscopy [60]. Although many fecal metabolites are common to the three species, such as short-chain fatty acids (SCFAs) and branched chain amino acids, each host species generates a unique metabolic profile when analyzed by multivariate analysis. This analysis refers to a suite of unsupervised (for example, principal component analysis) or supervised methods (for example, partial least squares discriminant analysis) for analyzing largescale spectroscopic data sets.

The biochemical composition of intact intestinal tissues (duodenum, jejunum, ileum, and proximal and distal colon) has recently been studied in germ-free mice inoculated with human baby microbiota, using magicangle-spinning NMR spectroscopy. The HBF-inoculated tissue metabolite profiles were then compared with those from conventional (that is, gnotobiotic mice transfected with normal mouse intestinal flora) and conventionalized mice (gnotobiotic mice transfected with $\mathrm{HBF}$ ). This demonstrated that biochemical topographical variation exists between intestinal regions that are specific for the microbiomes. In particular, osmolytes were affected and the duodenum had higher ethanolamine and myoinositol quantities, and the ileum had higher taurine and betaine levels than other gut regions. HBF mice showed lower taurine and myo-inositol levels in the colon, and all ex-germfree animals had higher taurine, choline and ethanolamine levels in the jejunum. Interestingly, the jejunum of HBF mice was marked by a higher glutathione level and lower concentrations of its precursor methionine when compared with other groups [61].

Top-down multivariate analysis of metabolic profiles also reveals a significant association of specific metabotypes with the resident microbiome. Martin et al. [62] derived a transgenomic graph model showing that $\mathrm{HBF}$ has a remarkably simple microbiome/metabolome correlation network, impacting directly on the ability of the host to metabolize lipids, and fundamentally altering the biliary enterohepatic circulation. This effect can also be measured in plasma using an approach based on mass spectrometry [54]. The production of indole-3-propionic acid was shown to be completely dependent on the presence of gut microflora, and could be established by colonization with the bacterium Clostridium sporogenes. Multiple organic acids containing phenyl groups were also greatly increased in the presence of gut microbes. More interestingly, a broad, phase II metabolic response of the host to metabolites generated by the microbiome was observed, suggesting that the gut microflora have a direct impact on drug metabolism.

This variation between individuals continues at a proteomic level. A non-targeted, shotgun mass-spectro- metry-based whole community proteomics, or metaproteomics, approach has been used for measurements of thousands of proteins in human fecal samples taken from two monozygotic twins. Analysis was performed using two-dimensional liquid chromatography-mass spectrometry/mass spectrometry [47]. In contrast to metagenomic data sets, the metaproteome had relatively more of its distribution attributed to translation, energy production and carbohydrate metabolism. Antimicrobial peptides were also identified, suggesting that the mammalian response to the gut microbiome can also be quantified. Several unknown proteins were also described for microbial pathways or host immune responses, revealing a novel complex interplay between the human host and its associated microbes. However, a significant problem arises with proteomic analysis, and this is that the number of unknown proteins far outweighs the number of unknown genes. This is likely to serve as a significant bottleneck in the functional use of proteomic data for use in future analysis of the gut microbiome.

The effect of the gut microbiota on drug metabolism has been previously explored, and the metabolic pathway of several drugs, such as L-DOPA, sulfasalazine, digoxin and even glyceryl trinitrate, has been established in the gut [63]. However, metabonomic approaches are creating new insights into commonly prescribed drugs, such as simvastatin, that were not previously appreciated. This is the most commonly prescribed statin in a billion dollar global market. It serves as an inhibitor of 3-hydroxy-3methylglutaryl coenzyme A, regulating hepatic cholesterol production. Simvastatin is degraded in the gut by hydrolytic cleavage of methylbutanoic acid from its backbone. Metabolism involves gut microbial processes of the demethylation of dimethylbutanoic acid, hydroxylation/dehydroxylation and $\beta$-oxidation, resulting in the production of 2-hydroxyisovaleric acid (3-methyl-2hydroxybutanoic acid), 3-hydroxybutanoic acid and lactic acid (2-hydroxypropanoic acid), and finally re-cyclization of heptanoic acid to produce cyclohexanecarboxylic acid [64]. The implication is significant, as there may be much greater variability of statin drug metabolism between individuals than is currently appreciated, and this serves as an example for the need for better personalized approaches to drug development.

Several disease states are now being linked with pathological variation in the gut microbiome using functional approaches such as metabonomics or proteomics and metagenome level analysis.

An exploration of the dominant bacteria in patients with colorectal cancer (CRC) was recently undertaken [65]. A significantly reduced temporal stability and increased diversity for the microbiota of subjects with CRC and polyposis was found using a $16 \mathrm{~S}$ rDNA DGGE analysis. A significantly increased diversity of the 
Clostridium leptum and Clostridium coccoides subgroups was also noted for both disease groups. A clear division in the metabonome was observed for the CRC and polypectomized subjects compared with control volunteers. The production of hydrogen sulfide, an end product of metabolism by the sulfate-reducing bacteria, has been cited as a potential etiological agent in gastrointestinal disease. Hydrogen sulfide has genotoxic, cytotoxic and inflammatory effects, and its inefficient metabolism by species of sulfate-reducing bacteria could have a critical impact on the health of the host. Therefore, in a separate study, the same authors used quantitative PCR to study a cohort of CRC and polypectomized patients. CRC patients had significantly lower numbers of Desulfovibrio species than healthy individuals, suggesting a possible new role for the gut bacteria in the mechanism of CRC.

Bacterial genes involved in regulation of NF- $\mathrm{kB}$ signaling in intestinal epithelial cells have been described recently using a HT-29 cell line, transfected with a plasmid containing the secreted alkaline phosphatase gene under the control of NF- $\mathrm{kB}$ binding elements [66]. Screening of 2,640 metagenomic clones led to the identification of 171 modulating clones and, among these, one stimulatory metagenomic clone, 52B7, was sequenced. This suggested that the metagenomic DNA insert might belong to a new Bacteroides strain, and two loci encoding an ATP-binding cassette transport system and a putative lipoprotein are potentially involved in the $52 \mathrm{~B} 7$ effect on NF-kB.

The gut microbiome has been extensively linked with IBD, and recently the 'hygiene hypothesis' has been implicated; this suggests that a reduction in microbial exposure as a result of improved health measures has contributed to an immunological imbalance in the intestine, and has increased the incidence of autoimmune diseases such as IBDs [67]. Culture-independent techniques are also providing new information on the gut ecology of these conditions. Specific bacterial populations are activated in patients with IBD, while other groups are in an inactive or 'dormant' state, such as the Actinobacteria and Firmicutes, while Escherichia species have been found to be both abundant and active in the Crohn's disease and ulcerative colitis groups [68]. Pseudomonas species are also less diverse in Crohn's disease patients compared with non-IBD patients. In particular Pseudomonas aeruginosa was only identified in non-IBD patients [69]. Irrespective, there is increasing evidence that the microbiome is able to directly influence the expression of the innate immune system via the Toll-like receptor (TLR) pathway [70]. Commensal bacteria are also vital for modulating the immune response, and SCFAs appear to be central to this process. New mechanisms of action for these important metabolites are being found; for example, SCFAs bind to the G-coupledprotein-receptor 43 and this is necessary for the resolution of certain inflammatory responses [71]. The hygiene hypothesis has therefore also been implicated in the etiology of asthma and atopy via a mechanism similar to that of the modulation of the innate immune response [72,73] (Figure 1).

The concept that intestinal microbial composition affects the health of the gut, and also influences centrally mediated systems involved in mood and mental health, is being increasingly reported. This is described by the gutbrain communication hypothesis, and it is possible that the gut microbiota have a role in the pathogenesis of psychiatric disorders such as depression, particularly when linked to conditions such as IBD [74]. Animal studies have provided evidence to suggest a modulating role for probiotic bacteria in immune, neuroendocrine and neurochemical responses outside the gastrointestinal tract [75]. Specifically, the absence of gastrointestinal microbes in mice results in reduced production of brainderived neurotrophic factor in the cortex and hippocampus, and an exaggerated hypothalamic-pituitaryadrenal axis response to stress [76]. A particularly interesting avenue of research has focused on the potential role of the gut microbiota in the mechanism of autism. Clostridium bolteae is significantly more prevalent in the gut of autistic children [77], and although the mechanism by which gut flora are able to initiate autism is as yet not elucidated, it has been hypothesized that this pathway may be of importance [10].

\section{Gut microbiome 'transplantation'}

Previous studies have confirmed that transplanted microbiota may be able to maintain their ecological stability in the host animal for 6 months [78] to 1 year [79]. This suggests that these models are robust enough to study the mechanism of human diseases, at least in the acute phase, although it is not yet known if this approach accurately reflects the importance of the gut microbiota to human health over a period of 'years'. However, shortto medium-term stability means that the metabolic potential of the gut microbiome can be harnessed for beneficial purposes, such as the treatment of antibioticassociated diarrhea. However, this approach does not always generate a positive outcome for the host. Such an effect was first reported by Turnbaugh et al. [7], who demonstrated that the obesity phenotype was transferable after feces from obese mice were transferred to lean animals. Moreover, the same altered microbiome was demonstrated in a human study of obesity in lean and obese twins [29]. The transfer of cholesterol metabolism characteristics has also been demonstrated in germfree rats. Gerard et al. [80] studied two groups of six, initially germ-free, rats associated with two groups of different human microbiota, which exhibited high and low cholesterol-reducing activities. Four months after 
inoculation, the rats harbored a raised coprostanoligenic bacterial population level and exhibited coprostanoligenic activities similar to those of the corresponding human donor.

Deep sequencing and phylogenetic clustering has been used to examine the long-term effects of exogenous microbiota transplantation combined with and without an antibiotic pretreatment [81]. As a result of transplantation, the intestinal bacterial diversity exceeded that of the human gut by a factor of two to three because of the capture of new phylotypes and an increase in abundance of others. However, antibiotic dosing prior to transplantation does not increase the establishment of the donor phylotypes, although some dominant lineages still transferred successfully. These effects were observed after 1 month of treatment, and persisted after 3 months. The authors concluded the gut microbial 'plasticity' is conditioned by the altered microbiome and that altered gut homeostasis was caused by antibiotic pretreatment rather than by the primary bacterial loss. This is corroborated by top-down systems metabolism approaches, which suggest a significant effect of antibiotics on host metabolism. Female mice dosed with oral vancomycin, and characterized using NMR spectroscopy of urine and fecal extract samples [82], demonstrated a higher fecal excretion of uracil, amino acids and SCFAs, highlighting the contribution of the gut microbiota to the production and metabolism of these dietary compounds. Comparison of urinary hippurate and phenylacetylglycine concentrations to the fecal metabolite profile revealed a strong association between these urinary metabolites and a wide range of fecal metabolites, suggesting a causal link between antibiotic use and an altered metabonome [83].

However, gut microbial modulation is not always initiated by medical intervention, and small bowel transplants used in cases of intestinal failure permit an opportunity for long-term study of the microbial ecology of the human small bowel. This is because an ileostomy is created during surgery for monitoring the progress of the allograft and this provides access to samples of ileal effluent and mucosal biopsies. Seventeen patients with small bowel transplants were recently studied over a period of 8 weeks and they had their ileal content measured by quantitative PCR [52]. This demonstrated a form of microbial 'metaplasia', where the normally strict anaerobic Bacteroides and Clostridium species were replaced by Lactobacillus and Enterobacteriacae, which are typically facultative anaerobes. After surgical closure of the ileostomy, the community reverted to the normal structure. Metabonomic profiling demonstrated enrichment for metabolites associated with aerobic respiration in samples from patients with open ileostomies, supporting the hypothesis that oxygen exposure was responsible for the change [53].

\section{Therapeutic implications of gut microbiome modulation}

The potential therapeutic role of the gut microbiota for human health has led to therapeutic approaches such as bacteriotherapy [83] and bioecological control [84]. Broadly, these theories argue that modulation of intestinal floral populations either by the pre-morbid gut microbiota of the host or by prebiotics, probiotics and synbiotics may be beneficial for human health [85]. Several studies now suggest that fecal transplantation may be beneficial in states of antibiotic-associated diarrhea or Clostridium difficile infection [86-88]. However, the long-term functional or metabolic consequences for the host of microbial modulation are poorly understood. New insights are being provided through the analysis of probiotic and prebiotic studies using global metabolic profiling techniques, where evidence suggests that the effect may be cumulative [45,89]. The effects of the probiotics Lactobacillus paracasei or Lactobacillus rhamnosus, and two galactosyl-oligosaccharide prebiotics, were studied in germ-free mice inoculated with HBF. When the therapies were combined, populations of Bifidobacterium longum and Bifidobacterium breve increased, and Clostridium perfringens decreased. These microbial effects were associated with modulation of a range of host metabolic pathways indicated by changes in lipid profiles, gluconeogenesis, and amino acid and methylamine metabolism, and were associated with fermentation of carbohydrates by different bacterial strains. Hierarchical-principal component analysis also permitted the visualization of multicompartmental transgenomic metabolic interactions that were also resolved at the compartment and pathway level. More novel approaches that incorporate parasites that interact with the gut microbiome have also been suggested, such as the use of helminths in IBD [90].

Probiotic therapies have now been proposed for a large variety of gut-related disorders such as IBD, inflammatory bowel syndrome and pouchitis after surgery for IBD. However, there are more novel areas of potential application. A recent study assessed the potential benefits of the probiotic Bifidobacterium infantis in the rat maternal separation model [91]. Maternal separation adult rat offspring were chronically treated with bifidobacteria or citalopram and subjected to the forced swim test to assess motivational state. Probiotic treatment resulted in normalization of the immune response, reversal of behavioral deficits after maternal separation and a forced swim test, and restoration of basal noradrenaline concentrations in the brainstem.

It is highly likely that more detailed information on the ecology of the gut will lead to more medical targets for colonic and systemic disease states. The first evidence of this approach is now emerging, as drugs may also be 
designed to inhibit undesirable enzyme activities in essential microbial symbiotes to enhance chemotherapeutic efficacy. Recently, a novel approach has been described through bacterial modulation of the doselimiting side effect of the common colon cancer chemotherapeutic CPT-11. This commonly causes severe diarrhea by reactivation of the symbiotic bacterial $\beta$ glucuronidases in the gut. Potent bacterial $\beta$-glucuronidase inhibitors have been identified by high-throughput screening and been shown to have no effect on the orthologous mammalian enzyme [92]. Inhibitors were highly effective against the enzyme target in living aerobic and anaerobic bacteria, but did not kill the bacteria or harm mammalian cells and oral administration of an inhibitor protected mice from CPT-11-induced toxicity. This suggests that the creation of personalized strategies for altering drug toxicity is readily achievable. This is corroborated by clinical trials showing that probiotics such as Bifidobacterium and Lactobacillus improve mood and reduce anxiety symptoms in patients with chronic fatigue syndrome and inflammatory bowel syndrome [76].

The concept of 'personalized' health care is therefore totally dependent on a better understanding of the gut microbiome from the top down and the bottom up $[25,93]$. Single probiotic agents are unlikely to dramatically alter long-term health across populations without targeted interventions based on a prior knowledge of the microbial requirements of a specific person. This is even more important in the diseased gut, where the ecosystem may already be deleteriously affected. Even the effective delivery of engineered bacteria for the delivery of endogenous therapeutic agents, which has been proposed for conditions such as IBD [94], will be dependent on a predictable ecosystem.

Bariatric surgery aims to reduce the volume of the stomach and increase transit times of food by diverting the flow of small bowel effluent through a gastric bypass procedure. Recently, 184,094 sequences of microbial 16S rRNA genes from PCR amplicons were examined using the 454 pyrosequencing technology to compare the microbial community structures of nine individuals: three in each of the categories of normal weight, morbidly obese, and post-gastric-bypass surgery [95]. Phylogenetic analysis demonstrated that although the bacteria in the human intestinal community were highly diverse, they fell mainly into six bacterial groups with distinctive divisions. Specifically, Firmicutes were dominant in normal-weight and obese individuals, but were significantly decreased in post-gastric-bypass individuals, who also had a proportional increase of Gammaproteobacteria. Hydrogen-producing Prevotellaceae were highly enriched in the obese individuals. Unlike the highly diverse bacteria, the archaea comprised mainly members of the order Methanobacteriales, which are hydrogenoxidizing methanogens. Using real-time PCR, significantly higher numbers of hydrogen-utilizing methanogenic archaea were detected in obese individuals than in normal-weight or post-gastric-bypass individuals. The authors hypothesized that interspecies hydrogen transfer between bacterial and archaeal species is an important mechanism for increasing energy uptake by the large intestine in obese persons [95]. It is difficult to definitively ascertain whether the surgical trauma, the bypass or the altered oral intake is definitively responsible. Nonetheless, the inference is that it may be possible to medically alter the entire gut microbial make-up of obese patients for the purpose of altering energy metabolism and thus weight loss. More importantly, gastric bypass patients with type II diabetes mellitus are rapidly and definitively cured of this condition [96]. Modern bariatric procedures therefore represent 'super system' surgery that seeks to alter the microbiome as part of the surgical procedure for the benefit of human health. If the intestinal microbiota are involved in this mechanism in some way, and it is highly likely that they are, then the treatment of type 2 diabetes mellitus by microbiotal modulation may represent an even more valuable drug target than surgery in the treatment of obesity.

Significantly, recent evidence suggests that mice genetically deficient in TLR5, a component of the innate immune system that is expressed in the gut mucosa and that helps defend against infection, exhibit hyperphagia and develop hallmark features of metabolic syndrome, including hyperlipidemia, hypertension, insulin resistance and increased adiposity [97]. These metabolic changes correlated with changes in the composition of the gut microbiota, and transfer of the gut microbiota from TLR5deficient mice to wild-type germ-free mice conferred many features of metabolic syndrome to the recipients, reciprocating work previously described by Turnbaugh et al. $[7,98]$. This suggests that the altered innate immune system may play a direct role in the method of microbial modulation of diabetes in the metabolic syndrome.

This theory is supported in part by metabonomic studies of obesity, because both lean and obese animals have specific metabolic phenotypes that are linked to their individual microbiomes. The two functionally and phenotypically normal Zucker rat strains (fa/- and -/-) were readily distinguished from the $(\mathrm{fa} / \mathrm{fa})$ obese rats on the basis of their metabotypes, with relatively lower levels of urinary hippurate and creatinine, relatively higher levels of urinary isoleucine, leucine and acetate, and higher plasma low-density lipoprotein and very low-density lipoprotein levels typifying the (fa/fa) obese strain [99]. Therefore, if truly personalized strategies that deliver an improved quality of care to patients are ever to be delivered for globally important health problems such as obesity, 
systems biology approaches that account for mammalian/ microbial mutualism at genomic, proteomic and metabolic levels are urgently required. These approaches will have an impact across medicine and surgery, and they will deliver the next generation of drug therapies.

\section{Conclusions}

Systems biology has irrevocably altered the view that mammalian metabolism is solely influenced by the human genome. A core gut microbiome may exist within the human gut, at least at a genomic or metabolic level, and this is fundamental to the maintenance of health, the development of disease and human metabolic processes. However, there is a large variation in the microbial content of the distal gut between individuals and populations, and it is sensitive to genomic, dietary, age, sex, pharmaceutical and even surgical interventions. Systems biology approaches at the metabonomic and proteomic level have greatly increased the potential of genomic strategies by providing a 'functional' analysis of gut microbial function, and this suggests that the biological mutualism is not only deeper than previously described, but it may also be modulated for the improvement of human health. Next-generation genomic technologies will lead to the development of experimental models that are more representative of the human gut microbiome for hypothesis testing. This, in turn, will expedite the discovery, testing and validation of novel drug targets. However, a rapid resolution of the bottleneck in the proteomic pipeline is now of the upmost importance if this vision is to be realized. Future metagenomic research is also likely to center on the complex relationships of the gut microbiome with the hundreds of other species of gut fungi, viruses, yeasts and parasites so that in time their true importance to human health will also be better understood. Computational modeling of the gut ecosystem at a systems level may yet permit advances in cellular engineering technologies that are able to utilize the microbiome for drug delivery, production and disease prevention targeted at the individual. But, even before this vision is realized, the gut microbiome will greatly contribute to the delivery of personalized healthcare strategies that are already being translated into the clinical environment for the benefit of patients.

\section{Abbreviations}

bp, base pair; CRC, colorectal cancer; DGGE, denaturing gradient gel

electrophoresis; HBF, human baby flora; HMA, human microbiota-associated; IBD, inflammatory bowel disease; NF, nuclear factor; NMR, nuclear magnetic resonance; $O R F$, open reading frame; $P C R$, polymerase chain reaction; rRNA, ribosomal RNA; SCFA, short-chain fatty acid; TLR, Toll-like receptor.

\section{Competing interests}

The authors have no competing interests.

\section{Authors' contributions}

JMK and AWD contributed equally to this work. JKN was responsible for the article design and content. JMK researched and wrote the body of the text.
AWD edited the paper for publication and provided critical analysis for the surgical component. All authors read and approved the final manuscript.

\section{Acknowledgements}

The authors would like to acknowledge the support of the NHS Institute for Health Research (NIHR) for the research groups continued funding through the Biological Research Centre.

\section{Author details}

'Section of Biosurgery and Surgical Technology, Department of Surgery and Cancer, Faculty of Medicine, Imperial College London, 10th Floor, QEQM, St Mary's Hospital, London W2 1NY, UK. ${ }^{2}$ Section of Bimolecular Medicine, Department of Surgery and Cancer, Faculty of Medicine, Imperial College London, The Sir Alexander Fleming Building, South Kensington, London SW7 2AZ, UK.

Published: 4 March 2011

\section{References}

1. Bengmark S: Ecological control of the gastrointestinal tract. The role of probiotic flora. Gut 1998, 42:2-7.

2. Gill SR, Pop M, Deboy RT, Eckburg PB, Turnbaugh PJ, Samuel BS, Gordon الر, Relman DA, Fraser-Liggett CM, Nelson KE: Metagenomic analysis of the human distal gut microbiome. Science 2006, 312:1355-1359.

3. Lederberg J: Infectious history. Science 2000, 288:287-293.

4. Dethlefsen L, MCFall-Ngai M, Relman DA: An ecological and evolutionary perspective on human-microbe mutualism and disease. Nature 2007, 449:811-818.

5. Vaughan EE, Schut F, Heilig HG, Zoetendal EG, de Vos WM, Akkermans AD: A molecular view of the intestinal ecosystem. Curr Issues Intest Microbiol 2000, 1:1-12.

6. Qin J, Li R, Raes J, Arumugam M, Burgdorf KS, Manichanh C, Nielsen T, Pons N Levenez F, Yamada T, Mende DR, Li J, XU J, Li S, Li D, Cao J, Wang B, Liang H, Zheng H, Xie Y, Tap J, Lepage P, Bertalan M, Batto JM, Hansen T, Le Paslier D, Linneberg A, Nielsen HB, Pelletier E, Renault P, et al:: A human gut microbial gene catalogue established by metagenomic sequencing. Nature 2010, 464:59-65.

7. Turnbaugh PJ, Ley RE, Mahowald MA, Magrini V, Mardis ER, Gordon J: An obesity-associated gut microbiome with increased capacity for energy harvest. Nature 2006, 444:1027-1031.

8. Holmes E, Loo RL, Stamler J, Bictash M, Yap IK, Chan Q, Ebbels T, De lorio M, Brown IJ, Veselkov KA, Daviglus ML, Kesteloot H, Ueshima H, Zhao L, Nicholson JK, Elliott P: Human metabolic phenotype diversity and its association with diet and blood pressure. Nature 2008, 453:396-400.

9. Marchesi JR, Holmes E, Khan F, Kochhar S, Scanlan P, Shanahan F, Wilson ID, Wang Y: Rapid and noninvasive metabonomic characterization of inflammatory bowel disease. J Proteome Res 2007, 6:546-551.

10. Finegold SM: Therapy and epidemiology of autism - clostridial spores as key elements. Med Hypotheses 2008, 70:508-511.

11. Clayton TA, Lindon JC, Cloarec O, Antti H, Charuel C, Hanton G, Provost JP, Le Net JL, Baker D, Walley RJ, Everett JR, Nicholson JK: Pharmaco-metabonomic phenotyping and personalized drug treatment. Nature 2006, 440:1073-1077.

12. Hooper LV, Gordon J: Commensal host-bacterial relationships in the gut. Science 2001, 292:1115-1118.

13. Macpherson AJ, Gatto D, Sainsbury E, Harriman GR, Hengartner H, Zinkernagel RM: A primitive T cell-independent mechanism of intestinal mucosal lgA responses to commensal bacteria. Science 2000, 288:2222-2226.

14. Kinross JM, Alkhamesi N, Barton RH, Silk DB, Yap IK, Darzi AW, Holmes E, Nicholson JK: Global metabolic phenotyping in an experimental laparotomy model of surgical trauma. J Proteome Res 2011, 10:277-287.

15. Nicholson JK, Holmes E, Wilson ID: Gut microorganisms, mammalian metabolism and personalized health care. Nat Rev Microbiol 2005, 3:431-438.

16. Mazmanian SK, Liu CH, Tzianabos AO, Kasper DL: An immunomodulatory molecule of symbiotic bacteria directs maturation of the host immune system. Cell 2005, 122:107-118.

17. Rakoff-Nahoum S, Paglino J, Eslami-Varzaneh F, Edberg S, Medzhitov R: Recognition of commensal microflora by toll-like receptors is required for intestinal homeostasis. Cell 2004, 118:229-241. 
18. Wilson ID, Nicholson JK: The role of gut microbiota in drug response. Curr Pharm Des 2009, 15:1519-1523.

19. Ley RE, Knight R, Gordon Jl: The human microbiome: eliminating the biomedical/environmental dichotomy in microbial ecology. Environ Microbiol 2007, 9:3-4

20. Costello EK, Lauber CL, Hamady M, Fierer N, Gordon Jl, Knight R: Bacterial community variation in human body habitats across space and time. Science 2009, 326:1694-1697.

21. Manichanh C, Varela E, Martinez C, Antolin M, Llopis M, Dore J, Giralt J, Guarner F, Malagelada JR: The gut microbiota predispose to the pathophysiology of acute postradiotherapy diarrhea. Am J Gastroenterol 2008, 103:1754-1761.

22. Ley RE, Peterson DA, Gordon Jl: Ecological and evolutionary forces shaping microbial diversity in the human intestine. Cell 2006, 124:837-848.

23. Sartor RB: Therapeutic manipulation of the enteric microflora in inflammatory bowel diseases: antibiotics, probiotics, and prebiotics. Gastroenterology 2004, 126:1620-1633.

24. Raibaud P: Experimental models for studying the microbial ecology in the intestinal tract. Acta Gastroenterol Latinoam 1989, 19:219-226.

25. Jia W, Li H, Zhao L, Nicholson JK: Gut microbiota: a potential new territory for drug targeting. Nat Rev Drug Discov 2008, 7:123-129.

26. Palmer C, BikEM, DiGiulio DB, Relman DA, Brown PO: Development of the human infant intestinal microbiota. PLoS Biol 2007, 5:e177.

27. Zoetendal EG, Akkermans AD, De Vos WM: Temperature gradient gel electrophoresis analysis of $16 \mathrm{~S}$ rRNA from human fecal samples reveals stable and host-specific communities of active bacteria. Appl Environ Microbiol 1998, 64:3854-3859.

28. Ley RE, Backhed F, Turnbaugh P, Lozupone CA, Knight RD, Gordon J: Obesity alters gut microbial ecology. Proc Natl Acad Sci US A 2005, 102:11070-11075.

29. Turnbaugh PJ, Hamady M, Yatsunenko T, Cantarel BL, Duncan A, Ley RE, Sogin ML, Jones WJ, Roe BA, Affourtit JP, Egholm M, Henrissat B, Heath AC, Knight R, Gordon J: A core gut microbiome in obese and lean twins. Nature 2009, 457:480-484.

30. Eckburg PB, Bik EM, Bernstein CN, Purdom E, Dethlefsen L, Sargent M, Gill SR, Nelson KE, Relman DA: Diversity of the human intestinal microbial flora. Science 2005, 308:1635-1638.

31. Kibe R, Sakamoto M, Hayashi H, Yokota H, Benno Y: Maturation of the murine cecal microbiota as revealed by terminal restriction fragment length polymorphism and 16S rRNA gene clone libraries. FEMS Microbiol Lett 2004, 235:139-146.

32. Licht TR, Madsen B, Wilcks A: Selection of bacteria originating from a human intestinal microbiota in the gut of previously germ-free rats. FEMS Microbiol Lett 2007, 277:205-209.

33. Kibe R, Sakamoto M, Yokota H, Benno Y: Characterization of the inhabitancy of mouse intestinal bacteria (MIB) in rodents and humans by real-time PCR with group-specific primers. Microbiol Immuno/ 2007, 51:349-357.

34. Tringe SG, Rubin EM: Metagenomics: DNA sequencing of environmenta samples. Nat Rev Genet 2005, 6:805-814.

35. von Mering C, Hugenholtz P, Raes J, Tringe SG, Doerks T, Jensen L, Ward N, Bork P: Quantitative phylogenetic assessment of microbial communities in diverse environments. Science 2007, 315:1126-1130.

36. Riesenfeld CS, Schloss PD, Handelsman J: Metagenomics: genomic analysis of microbial communities. Annu Rev Genet 2004, 38:525-552.

37. Kurokawa K, Itoh T, Kuwahara T, Oshima K, Toh H, Toyoda A, Takami H, Morita H, Sharma VK, Srivastava TP, Taylor TD, Noguchi H, Mori H, Ogura Y, Ehrlich DS, Itoh K, Takagi T, Sakaki Y, Hayashi T, Hattori M: Comparative metagenomics revealed commonly enriched gene sets in human gut microbiomes. DNA Res 2007, 14:169-181.

38. Madara JL, Nash S, Moore R, Atisook K: Structure and function of the intestinal epithelial barrier in health and disease. Monogr Patho/ 1990 31:306-324

39. Turnbaugh PJ, Hamady M, Yatsunenko T, Cantarel BL, Duncan A, Ley RE, Sogin ML, Jones WJ, Roe BA, Affourtit JP, Egholm M, Henrissat B, Heath AC, Knight R, Gordon J: A core gut microbiome in obese and lean twins. Nature 2009, 457:480-484.

40. Swanson KS, Dowd SE, Suchodolski JS, Middelbos IS, Vester BM, Barry KA, Nelson KE, Torralba M, Henrissat B, Coutinho PM, Cann IK, White BA, Fahey GC $\mathrm{Jr}$ : Phylogenetic and gene-centric metagenomics of the canine intestinal microbiome reveals similarities with humans and mice. ISME J 2011 5:639-649.

41. MG-RAST [http://metagenomics.nmpdr.org/]
42. Peleg AY, Hogan DA, Mylonakis E: Medically important bacterial-fungal interactions. Nat Rev Microbiol, 8:340-349.

43. Ghannoum MA, Jurevic RJ, Mukherjee PK, Cui F, Sikaroodi M, Naqvi A, Gillevet PM: Characterization of the oral fungal microbiome (mycobiome) in healthy individuals. PLoS Pathog 2010 6:e1000713.

44. Reyes A, Haynes M, Hanson N, Angly FE, Heath AC, Rohwer F, Gordon J: Viruses in the faecal microbiota of monozygotic twins and their mothers. Nature 2010 466:334-338

45. Turroni F, Marchesi JR, Foroni E, Gueimonde M, Shanahan F, Margolles A van Sinderen D, Ventura M: Microbiomic analysis of the bifidobacterial population in the human distal gut. ISME J 2009, 3:745-751.

46. Martin FP, Wang Y, Sprenger N, Yap IK, Rezzi S, Ramadan Z, Pere-Trepat E, Rochat F, Cherbut C, van Bladeren P, Fay LB, Kochhar S, Lindon JC, Holmes E, Nicholson JK: Top-down systems biology integration of conditional prebiotic modulated transgenomic interactions in a humanized microbiome mouse model. Mol Syst Biol 2008, 4:205.

47. Verberkmoes NC, Russell AL, Shah M, Godzik A, Rosenquist M, Halfvarson J, Lefsrud MG, Apajalahti J, Tysk C, Hettich RL, Jansson JK: Shotgun metaproteomics of the human distal gut microbiota. Isme J 2009 3:179-189.

48. Nicholson JK, Lindon JC, Holmes E: 'Metabonomics': understanding the metabolic responses of living systems to pathophysiological stimuli via multivariate statistical analysis of biological NMR spectroscopic data. Xenobiotica 1999, 29:1181-1189.

49. Kanazawa H, Nagino M, Kamiya S, Komatsu S, Mayumi T, Takagi K, Asahara T, Nomoto K, Tanaka R, Nimura Y: Synbiotics reduce postoperative infectious complications: a randomized controlled trial in biliary cancer patients undergoing hepatectomy. Langenbecks Arch Surg 2005, 390:104-113.

50. Alverdy JC, Chang EB: The re-emerging role of the intestinal microflora in critical illness and inflammation: why the gut hypothesis of sepsis syndrome will not go away. J Leukoc Biol 2008, 83:461-466.

51. Nicholson JK, Holmes E: Global systems biology and personalized healthcare solutions. Discov Med 2006, 6:63-70.

52. Li M, Wang B, Zhang M, Rantalainen M, Wang S, Zhou H, Zhang Y, Shen J, Pang X, Wei H, Chen Y, Lu H, Zuo J, Su M, Qiu Y, Jia W, Xiao C, Smith LM, Yang S, Holmes E, Tang H, Zhao G, Nicholson JK, Li L, Zhao L: Symbiotic gut microbes modulate human metabolic phenotypes. Proc Natl Acad Sci U S A $2008,105 \cdot 2117-2122$

53. Hartman AL, Lough DM, Barupal DK, Fiehn O, Fishbein T, Zasloff M, Eisen JA: Human gut microbiome adopts an alternative state following small bowel transplantation. Proc Natl Acad Sci U S A 2009, 106:17187-17192.

54. Wikoff WR, Anfora AT, Liu J, Schultz PG, Lesley SA, Peters EC, Siuzdak G: Metabolomics analysis reveals large effects of gut microflora on mammalian blood metabolites. Proc Natl Acad Sci U S A 2009 106:3698-3703.

55. Nicholson JK, Connelly J, Lindon JC, Holmes E: Metabonomics: a platform for studying drug toxicity and gene function. Nat Rev Drug Discov 2002, 1:153-161.

56. Brindle JT, Antti H, Holmes E, Tranter G, Nicholson JK, Bethell HW, Clarke S, Schofield PM, McKilligin E, Mosedale DE, Grainger DJ: Rapid and noninvasive diagnosis of the presence and severity of coronary heart disease using 1H-NMR-based metabonomics. Nat Med 2002, 8:1439-1444.

57. Dumas ME, Wilder SP, Bihoreau MT, Barton RH, Fearnside JF, Argoud K, D'Amato L, Wallis RH, Blancher C, Keun HC, Baunsgaard D, Scott J, Sidelmann UG, Nicholson JK, Gauguier D: Direct quantitative trait locus mapping of mammalian metabolic phenotypes in diabetic and normoglycemic rat models. Nat Genet 2007, 39:666-672.

58. Stella C, Beckwith-Hall B, Cloarec O, Holmes E, Lindon JC, Powell J, van der Ouderaa F, Bingham S, Cross AJ, Nicholson JK: Susceptibility of human metabolic phenotypes to dietary modulation. J Proteome Res 2006 , 5:2780-2788

59. Clayton TA, Baker D, Lindon JC, Everett JR, Nicholson JK: Pharmacometabonomic identification of a significant host-microbiome metabolic interaction affecting human drug metabolism. Proc Nat/ Acad Sci USA 2009, 106:14728-14733.

60. Saric J, Wang Y, Li J, Coen M, Utzinger J, Marchesi JR, Keiser J, Veselkov K, Lindon JC, Nicholson JK, Holmes E: Species variation in the fecal metabolome gives insight into differential gastrointestinal function. J Proteome Res 2008, 7:352-360.

61. Martin FP, Wang Y, Yap IK, Sprenger N, Lindon JC, Rezzi S, Kochhar S, Holmes E, Nicholson JK: Topographical variation in murine intestinal metabolic 
profiles in relation to microbiome speciation and functional ecological activity. J Proteome Res 2009, 8:3464-3474

62. Martin FP, Dumas ME, Wang Y, Legido-Quigley C, Yap IK, Tang H, Zirah S, Murphy GM, Cloarec O, Lindon JC, Sprenger N, Fay LB, Kochhar S, van Bladeren P, Holmes E, Nicholson JK: A top-down systems biology view of microbiome-mammalian metabolic interactions in a mouse model. Mol Syst Biol 2007, 3:112.

63. Sousa T, Paterson R, Moore V, Carlsson A, Abrahamsson B, Basit AW: The gastrointestinal microbiota as a site for the biotransformation of drugs. Int J Pharm 2008, 363:1-25.

64. Aura AM, Mattila I, Hyotylainen T, Gopalacharyulu P, Bounsaythip C, Oresic M, Oksman-Caldentey KM: Drug metabolome of the Simvastatin formed by human intestinal microbiota in vitro. Mol Biosyst 2011, 7:437-446.

65. Scanlan PD, Shanahan F, Clune Y, Collins JK, O'Sullivan GC, O'Riordan M, Holmes E, Wang Y, Marchesi JR: Culture-independent analysis of the gut microbiota in colorectal cancer and polyposis. Environ Microbiol 2008, 10:789-798

66. Lakhdari O, Cultrone A, Tap J, Gloux K, Bernard F, Ehrlich SD, Lefevre F, Dore J, Blottiere HM: Functional metagenomics: a high throughput screening method to decipher microbiota-driven NF-kappaB modulation in the human gut. PLoS One 2010, 5:e13092.

67. Singhal S, Dian D, Keshavarzian A, Fogg L, Fields JZ, Farhadi A: The role of oral hygiene in inflammatory bowel disease. Dig Dis Sci 2010, 56:170-175.

68. Rehman A, Lepage P, Nolte A, Hellmig S, Schreiber S, Ott SJ: Transcriptional activity of the dominant gut mucosal microbiota in chronic inflammatory bowel disease patients. J Med Microbiol 2010, 59:1114-1122.

69. Wagner J, Short K, Catto-Smith AG, Cameron DJ, Bishop RF, Kirkwood CD: Identification and characterisation of Pseudomonas $16 \mathrm{~S}$ ribosomal DNA from ileal biopsies of children with Crohn's disease. PLoS One 2008, 3:e3578.

70. Fukata M, Abreu MT: TLR4 signalling in the intestine in health and disease. Biochem Soc Trans 2007, 35:1473-1478

71. Maslowski KM, Vieira AT, Ng A, Kranich J, Sierro F, Yu D, Schilter HC, Rolph MS, Mackay F, Artis D, Xavier RJ, Teixeira MM, Mackay CR: Regulation of inflammatory responses by gut microbiota and chemoattractant receptor GPR43. Nature 2009, 461:1282-1286.

72. Bjorksten B: Effects of intestinal microflora and the environment on the development of asthma and allergy. Springer Semin Immunopathol 2004 25:257-270.

73. Vael C, Desager K: The importance of the development of the intestinal microbiota in infancy. Curr Opin Pediatr 2009, 21:794-800.

74. O'Mahony SM, Marchesi JR, Scully P, Codling C, Ceolho AM, Quigley EM, Cryan JF, Dinan TG: Early life stress alters behavior, immunity, and microbiota in rats: implications for irritable bowel syndrome and psychiatric illnesses. Biol Psychiatry 2009, 65:263-267.

75. Girard SA, Bah TM, Kaloustian S, Lada-Moldovan L, Rondeau I, Tompkins TA, Godbout R, Rousseau G: Lactobacillus helveticus and Bifidobacterium longum taken in combination reduce the apoptosis propensity in the limbic system after myocardial infarction in a rat model. Br J Nutr 2009, 102:1420-1425.

76. Rao AV, Bested AC, Beaulne TM, Katzman MA, lorio C, Berardi JM, Logan AC: A randomized, double-blind, placebo-controlled pilot study of a probiotic in emotional symptoms of chronic fatigue syndrome. Gut Pathog 2009, 1:6.

77. Song Y, Liu C, Finegold SM: Real-time PCR quantitation of clostridia in feces of autistic children. Appl Environ Microbiol 2004, 70:6459-6465.

78. Hambly RJ, Rumney CJ, Cunninghame M, Fletcher JM, Rijken PJ, Rowland IR: Influence of diets containing high and low risk factors for colon cancer on early stages of carcinogenesis in human flora-associated (HFA) rats. Carcinogenesis 1997, 18:1535-1539.

79. Alpert C, Sczesny S, Gruhl B, Blaut M: Long-term stability of the human gut microbiota in two different rat strains. Curr Issues Mol Bio/ 2008, 10:17-24.

80. Gerard P, Beguet F, Lepercq P, Rigottier-Gois L, Rochet V, Andrieux C, Juste C: Gnotobiotic rats harboring human intestinal microbiota as a model for studying cholesterol-to-coprostanol conversion. FEMS Microbiol Ecol 2004 47:337-343.

81. Manichanh C, Reeder J, Gibert P, Varela E, Llopis M, Antolin M, Guigo R, Knight $R$, Guarner F: Reshaping the gut microbiome with bacterial transplantation and antibiotic intake. Genome Res 2010, 20:1411-1419.

82. Yap IK, Li JV, Saric J, Martin FP, Davies H, Wang Y, Wilson ID, Nicholson JK,
Utzinger J, Marchesi JR, Holmes E: Metabonomic and microbiological analysis of the dynamic effect of vancomycin-induced gut microbiota modification in the mouse. J Proteome Res 2008, 7:3718-3728.

83. Borody TJ, Warren EF, Leis SM, Surace R, Ashman O, Siarakas S: Bacteriotherapy using fecal flora: toying with human motions. J Clin Gastroenterol 2004, 38:475-483.

84. Bengmark S: Bioecologic control of the gastrointestinal tract: the role of flora and supplemented probiotics and synbiotics. Gastroenterol Clin North Am 2005, 34:413-436, viii.

85. Gibson GR, Roberfroid MB: Dietary modulation of the human colonic microbiota: introducing the concept of prebiotics. J Nutr 1995, 125:1401-1412.

86. Borody TJ: 'Flora Power' - fecal bacteria cure chronic C. difficile diarrhea. Am J Gastroenterol 2000, 95:3028-3029.

87. You DM, Franzos MA, Holman RP: Successful treatment of fulminant Clostridium difficile infection with fecal bacteriotherapy. Ann Intern Med 2008, 148:632-633.

88. Khoruts A, Dicksved J, Jansson JK, Sadowsky MJ: Changes in the composition of the human fecal microbiome after bacteriotherapy for recurrent Clostridium difficile-associated diarrhea. J Clin Gastroenterol 2010, 44:354-360.

89. Martin FP, Wang Y, Sprenger N, Yap IK, Lundstedt T, Lek P, Rezzi S, Ramadan Z, van Bladeren P, Fay LB, Kochhar S, Lindon JC, Holmes E, Nicholson JK: Probiotic modulation of symbiotic gut microbial-host metabolic interactions in a humanized microbiome mouse model. Mol Syst Biol 2008 , 4:157.

90. Guarner F: Prebiotics, probiotics and helminths: the'natural'solution? Dig Dis 2009, 27:412-417.

91. Desbonnet L, Garrett L, Clarke G, Kiely B, Cryan JF, Dinan TG: Effects of the probiotic Bifidobacterium infantis in the maternal separation model of depression. Neuroscience 2010, 170:1179-1188.

92. Wallace BD, Wang H, Lane KT, Scott JE, Orans J, Koo JS, Venkatesh M, Jobin C, Yeh LA, Mani S, Redinbo MR: Alleviating cancer drug toxicity by inhibiting a bacterial enzyme. Science 2010, 330:831-835

93. Shanahan F: Therapeutic implications of manipulating and mining the microbiota. J Physiol 2009, 587:4175-4179.

94. Hamady ZZ, Scott N, Farrar MD, Lodge JP, Holland KT, Whitehead T, Carding SR: Xylan-regulated delivery of human keratinocyte growth factor- 2 to the inflamed colon by the human anaerobic commensal bacterium Bacteroides ovatus. Gut 2010, 59:461-469.

95. Zhang H, DiBaise JK, Zuccolo A, Kudrna D, Braidotti M, Yu Y, Parameswaran P, Crowell MD, Wing R, Rittmann BE, Krajmalnik-Brown R: Human gut microbiota in obesity and after gastric bypass. Proc Natl Acad Sci U S A 2009 106:2365-2370.

96. Rubino F: Is type 2 diabetes an operable intestinal disease? A provocative yet reasonable hypothesis. Diabetes Care 2008, 31 Suppl 2:S290-296.

97. Vijay-Kumar M, Aitken JD, Carvalho FA, Cullender TC, Mwangi S, Srinivasan S, Sitaraman SV, Knight R, Ley RE, Gewirtz AT: Metabolic syndrome and altered gut microbiota in mice lacking Toll-like receptor 5. Science 2010, 328:228-231.

98. Turnbaugh PJ, Ridaura VK, Faith JJ, Rey FE, Knight R, Gordon J: The effect of diet on the human gut microbiome: a metagenomic analysis in humanized gnotobiotic mice. SciTrans/ Med 2009, 1:6ra14

99. Waldram A, Holmes E, Wang Y, Rantalainen M, Wilson ID, Tuohy KM, McCartney AL, Gibson GR, Nicholson JK: Top-down systems biology modeling of host metabotype-microbiome associations in obese rodents. J Proteome Res 2009, 8:2361-2375.

100. Turnbaugh PJ, Gordon Jl: The core gut microbiome, energy balance and obesity. J Physio/ 2009, 587:4153-4158.

101. Koenig JE, Spor A, Scalfone N, Fricker AD, Stombaugh J, Knight R, Angenent LT, Ley RE: Microbes and Health Sackler Colloquium: succession of microbial consortia in the developing infant gut microbiome. Proc Natl Acad Sci U S A 2011, 108 Suppl 1:4578-4585.

\section{doi:10.1186/gm228}

Cite this article as: Kinross JM, et al:: Gut microbiome-host interactions in health and disease. Genome Medicine 2011, 3:14. 